\title{
Complexity Science and Professional Learning for Collaboration: a critical reconsideration of possibilities and limitations
}

\author{
Tara Fenwick, University of Stirling
}

\begin{abstract}
Professionals increasingly must collaborate very closely, such as through inter-professional work arrangements. This involves learning both in and for collaboration. Some educational researchers have turned to complexity science to better understand these learning dynamics. This discussion asks, How useful is complexity science for examining professional learning in collaboration? After introducing complexity principles that appear in accounts of professional practice and education, selected studies are presented that draw from complexity science to examine professional collaboration in fields of management, social and health care, and education. A critical discussion of these studies points out oversights and limitations. Complexity theory is concluded to offer useful insights for two areas: (1) articulating complexities of professional practice and knowledge; and (2) providing educational support for professional knowing-inundecidability. However, it is also argued that complexity analyses of professional collaboration could do much more to exploit the explanatory power of complexity concepts, by returning to rich dynamics of strong emergence in a sociomaterialist analysis, and by avoiding metaphorical uses of complexity. Used rigorously rather than romantically, complexity concepts may prove more useful not only in analysing political dynamics of collaborative professional practice, but also in opening new questions and approaches for future research in professional learning.
\end{abstract}

Key words: Complexity science, professional collaboration, professional learning, health care, emergence

\section{Introduction}

An important contributor to the growing complexity of professionals' everyday practice is the widespread injunction for them to collaborate closely with other professionals, such as through inter-professional work arrangements. This involves learning both in collaboration, developing new co-productive approaches to practice, and for collaboration, developing capacities for engaging with diverse and even conflicting professional traditions. One example of this injunction is the continuing emphasis on 'professional learning communities' (Bolam et al. 2005; Dufour and Eaker 1998), within work organisations such as schools, grounded in notions of community and collaborative enquiry. Another example is the growing policy demand for multi-professional units spanning across organisations, such as those developed in the UK to improve social services for vulnerable children and youth involving, for example, nurses, psychiatrists, educators, social workers, and teachers (Edwards et al. 2009). Such forms of multiprofessional collaboration present new layers of complexity through disjunctures among professional knowledge cultures and conflicting boundaries of practice and professional responsibility. Multi-professional collaboration often invokes different language and categories used to conceptualise shared issues, and lacks clear procedures to guide new 
collaborative practices. As critiques of professional 'communities of practice' models have often noted (Barton and Hamilton 2005; Engeström 2009, Frankham 2006), the more difficult dynamics of language, politics, and history in collaboration often remain undertheorised or at least not discussed in any great depth, as though collaborative practice and learning is about simply learning to get along.

To better understand the dynamics of professionals' collaborative learning in such work arrangements, as well as to develop better supports for this learning through continuing professional development (CPD) or work-based learning opportunities, a number of educational researchers have turned to complexity science. In fact, it is fair to note a rather significant movement arising that has been linking complexity with education ${ }^{1}$. Complexity science, a highly heterogeneous domain, is impossible to describe accurately in a few sentences. However for purposes of this discussion, complexity can be represented as a radically holistic analysis that does not separate person from context, but shows how all things (individuals, tools, technologies, ideas, environments) are continually brought forth in dynamic systems or 'assemblages' of 'vital materiality' (Bennett 2010). These systems emerge in unpredictable ways through non-linear dynamics of mutual interaction and influence, producing a whole that is greater than the sum of its parts.

Educators in particular have adopted the notion that all complex systems ${ }^{2}$ are 'learning systems' (Davis and Sumara 2006). Educational researchers have also adopted particular concepts from complexity science that will be explained further on, such as emergence, nested systems, and self-organisation, to analyse processes in curriculum, policy, teaching/learning, and educational change, and to propose new educative approaches. Particularly in the area of professional practice and learning, a body of work has developed that promotes the value of complexity science for analysing collaborative and inter-professional work, and for suggesting approaches to enhance professional learning in this work (Haggis 2009; McMurtry 2007; Wolf-Branigin 2009; Zellermayer and Margolin 2005).

However, it is prudent to use caution when applying complexity science, with its assumptions and framings originally derived from mathematical and ecological systems, to socio-political domains of human activity. One might argue for particular caution when examining professionals' learning and practice. These unfold in highly contested systems of work and community, where multiple forms of regulation compete to define good practice and desirable learning. Indeed, some complexity writing for professional

\footnotetext{
${ }^{1}$ In Anglo-American arenas, at least, evidence includes several recent books (e.g. Davis and Sumara 2006; Mason 2008a; Osberg and Biesta 2010), a journal (Complicity, inaugurated in 2004), an annual international conference dedicated to complexity studies in education, an annual meeting of complexity theorists at the large American Educational Research Association, and special issues of educational journals featuring complexity studies (e.g., Mason 2008b; Osberg 2008).

2 Note that many systems are not complex (that is, open, dynamic, unpredictable, and so forth). Some systems are simple (knowable, predictable). Some are complicated (many interconnected parts, but still knowable and predictable) like a car or a watch. A school building is a complicated system; school life is a complex system.
} 
and organisational practice drifts into romantic and naïve notions of 'flow' and 'interconnectivity' of all living things. As argued elsewhere (Fenwick 2001), some appear to appropriate complexity rhetoric of continuous learning and self-organising systems to discipline workers for capitalist interests. Further, as Paley (2007) notes about complexity theory in the nursing field, assertions can easily circulate that are just plain wrong: such as that self-organisation is inherently a democratic process, that complexity theory distinguishes between competency and capability, or that complexity is a vision for an organisation.

In the field of education, critics have questioned complexity's capacity to address issues of responsibility or the political (Fenwick 2009; Phelan 2004). Important questions, perhaps particularly in considering professional education and practice, may seem invisible in complexity analyses. How does power flow within a system to enact particular entities, positions and rewards? What knowledge and activities, among the various relations and processes occurring within a complex system, are afforded the greatest visibility and influence over the movements and directions of the system? Whose interests are most advantaged or disadvantaged by the patterns that emerge? Complexity advocates have responded to these sorts of questions, as shown further on. The critical point here, perhaps, is that in considering the analytic potential of complexity science for professional learning, we should avoid 'over-hasty adoption' or 'a tendency to get hold of the wrong end of the stick' (Paley 2007, 233)

What, then, can complexity science contribute to understanding and supporting professional learning in collaboration? What is its potential, and its limitations? These are the questions addressed by the following discussion. The account begins with an overview of key principles and approaches in complexity science that appear to have particular salience for educational researchers, especially those studying professional learning and education. The second section presents examples of published studies employing complexity principles to examine collaborative professional practice and learning. These were selected to reflect issues of learning for and in collaboration examined in diverse disciplinary contexts: management, social services, health care, and education. They are intended to be indicative rather than representative or comprehensive. They illustrate usages of complexity concepts to both explain and to educate in particular ways. The third section critically discusses contributions and limitations in applying complexity principles to study professional collaboration that may be discerned in these examples. The final section argues overall that while complexityinspired analyses have illustrated important insights about professional practice, they could better exploit the full explanatory power available through more rigorous use of complexity principles. It concludes with suggestions for future study using complexity science to explore professional learning for and in collaboration.

\section{Complexity Approaches in Education and Work - Key Principles}

Complexity as an area of study is highly heterogeneous, its different lines of development having originated in diverse research practices, purposes and analytic models: mathematical fractals, evolutionary biology, family studies, cybernetics and simulated 
models, general systems theory, and so forth (see Alhadeff-Jones, 2008 for a summary of this development).

Amidst this heterogeneity, educational analyses using complexity ideas, such as those addressing professionals' learning and education, focus on some complexity principles more than others. This section offers a brief overview of these principles only, rather than addressing a wide range of complexity ideas. However, it is important to underline that these principles in no way provide a definitive statement of complexity science. We can only speculate as to the reasons why they have become prominent in educational studies. Perhaps researchers believe them to exercise superior explanatory power for educational phenomena, or to be more aligned with educational theory and language. With this caveat the following discussion will focus on complexity principles of emergence and nested systems, critical elements of emergence including uncertainty, non-linear dynamics, internal diversity, perturbation and feedback loops, and effects of emergence including self-organisation and the tension of disorder and order.

A central understanding in complexity is emergence. Phenomena, events and actors are viewed as mutually dependent, mutually constitutive, and actually emerge together in dynamic structures (Davis and Sumara 2008; Osberg and Biesta 2008). That is, the nature of any complex adaptive system (a city, a neighbourhood, a human mind, a political event, a particular professional practice, a spreading virus, etc) as well its elements and their relationships - both human and non-human - emerge through the continuous rich and recursive interactions among these elements. Humans are fully interconnected with other material elements of the systems that are constantly acting upon each other. No clear lines of causation or human intention can be traced from these interactions to their outcomes.

In educational uptakes of complexity theory, what is emphasised are the relations among things - not the things themselves (e.g. see Davis and Sumara 2006; Haggis 2008; Karpiak 2000; Mason 2008b; Osberg and Biesta 2007, 2008). The focus is not upon isolated actors and objects foregrounded against some contextual backdrop, but on the dynamic, nonlinear actions and connections flowing between all these parts. Complexity theory interrupts the natural tendency to seek clear boundaries between figures(objects) and grounds(context), and focuses on the relationships binding humans and non-humans together in multiple fluctuations. Thus, the boundaries between self and non-self (nature as well as society) are actually more permeable and the flow between them more continuous than we might be prepared to accept.

Yet all is not simply flow. Living systems are distinct, and move within and alongside one another as nested systems. A human body, for example, relies on highly specialised sub-systems that not only each respond to different circumstances and different needs, but also have learned to co-habitate and communicate with one another. Humans - as well as objects and energies - are nested within various systems of geographical arrangements, weather, political discourses, racialised identities and so forth. All complex systems can be viewed as being nested within one another, co-implicated and co- 
habitating. Yet each retains their own distinct identity, organising logic and emerging patterns.

Within and among systems, then, countless elements are constantly interacting and improvising simultaneously. Uncertainty is a central structural principle within these dynamic processes (Barad 2003; Stacey 1998). So many things are going on all at once and so many new possibilities are emerging that there can be no reduction of the system's patterns to [simple/linear] causes and effects. Among these possibilities, it is impossible to predict which will most influence what will happen next. This is partly because the principles influencing the system's choices for action and knowledge are not already given in the system's present patterns or its parts. Therefore, the future of the system can be nowhere evident in the patterns of the present system (Osberg, Biesta and Cilliers 2008).

How does emergence occur? The Nobel prize-winning physical chemist Ilya Prigogine (1997) showed how complex systems, which he characterised as 'far from equilibrium', develop themselves through non-linear dynamics of interaction. He demonstrated that within a complex system, choices are continually being made among alternatives that are presented to the system. Many of these alternatives emerge from within the system and seem to be chosen totally by chance because no possible calculation can demonstrate the system's preference for one or another. As each choice is adopted, the system changes and a new range of choices opens. A system thus unfolds in a series of 'jumps' influenced at each turn by something from within itself that is indeterminate and has no concrete existence (chance), but that irreversibly changes the system and its logic, and expands the possibilities available for its next actions. Important to note about Prigogine's work is that the system moves from near-equilibrium to a complex state farfrom-equilibrium through the application of energy: thermal energy, in his own studies. Something must stimulate perturbance in the system.

The possibility of emergence also depends upon internal diversity (Davis and Sumara 2006): diverse responses from the parts of a system, diverse elements elaborating small variations, diverse interactions generating novel information or energy, and so forth. Diversity enables the system to continually generate new possibilities, and diversity enables the resilience allowing the system to sustain itself throughout challenges and losses. Diversity alone is not sufficient, as Prigogine demonstrated. There must be interaction. Within masses of interaction, the smaller parts of the system become energised and sensitive to even minor fluctuations. The result is a complex system's continuous state of uncertainty and surprise, such that chance is always operating in the unfolding configurations, which are always opening a multiplicity of possibilities. Osberg $(2008,150)$ shows how Prigogine's conceptions are particularly valuable for education. In education, as in complex systems, 'what is already present is reordered or renewed in a way that opens incalculable (and wider) possibilities. In this sense, the non-deterministic "logic" of emergence can be thought of as a logic of renewal'.

Positive feedback loops are important in understanding how a system evolves and transforms, often unpredictably, and usually irreversibly. These are different from the notion of negative feedback, which in earlier systems theories was thought to sense minor 
deviations and drive a system back to its norm of equilibrium. Positive feedback amplifies perturbations in the system, potentially creating a momentum and distribution of small events that give rise to large system effects. Escalating feedback loops mobilise non-linear dynamics that can shift a repeated preference into obsessions or even addictions, or amplify small whorls of warm air and water into extreme weather patterns. With sufficient momentum, a system can pass a particular threshold or tipping point and shift into a new state. These emergences are recursive, continuing to elaborate what is present and what is possible in the system. Out of these continuous and non-linear interactions emerge dynamic structures that exceed their parts. Osberg and Biesta (2007) call this 'strong emergence'. What emerges is more than the sum of its parts, and therefore not predictable from the ground from which it emerges.

Emergence not only enables continuous adaptive change, it also enable self-organisation. Through the multiple interactions among diverse elements, usually according to local rules and not to some global pattern, a clear structure emerges without being imposed through any authority or planning. What Davis (2004: 151) calls a 'transcendent collectivity' emerges through the bottom-up interactions of multiple agents, to produce an identifiable unity and coherence. At the same time, top-down constraints are produced by this collectivity on its parts. Other dynamics required in self-organisation are redundancy or sufficient overlap among the agents (such as shared texts, language, interests) to enable the interactions that will give rise to the system, proximity among agents so they can affect one another, and a decentralised, distributed form of organisation. New novel forms of order are continually emerging, but the system usually will continue to maintain its identity except in the condition of severe perturbations when it may tip over a threshold to form a new state. As educational philosopher Bai $(2001,26)$ writes, 'changes are the result of our interpenetrating the world', more than of human conscious intentional action to do something.

This is not to say that the system organises in complete chaos, with no limitations or direction other than random pursuit of possibilities. There are always disordering dynamics held in tension with ordering patterns. A system encounters and contains many forms of limitation that affects its patterns. For example, self-organisation is necessarily limited by information such as memory and historical routines, embedded codes such as genetic structures, pre-existing objects and their properties that function within the system, and languages. This information does not predetermine and foreclose the directions of the system, for the information itself is subject to adaptation and shifts as emergence occurs. What it does mean, argue Smith and Jenks (2005), is that a notion of utter contingency is overly simplistic. A system needs different kinds of information. In fact, a complex system has simultaneous needs for both precise directions and 'loose' contingent information: 'self-organisation does not take place against a general background of contingency; rather, chaos and self-organisation determine each other somewhat in the form of degrees or "landscapes" of possibility or impossibility' (Smith and Jenks 2005, $153)$.

\section{Studies of Professional Learning and Education Using Complexity}

These concepts of emergence, nested systems, non-linear dynamics and uncertainty, internal diversity, positive feedback, self-organisation, and the tension of order and disorder all have been 
taken up in studies of professional learning and education. In considering the implications of complexity for lifelong learning and continuing professional education, Haggis (2009) argues that emergence helps move beyond preoccupations with activity and practice, to understand how activity, discourse, intentionality, biology and location together produce emergent effects across a range of embedded and mutually implicated systems.

If a person is conceptualised as an embedded dynamic system, then the question is no longer how people create understanding/meaning (cognitive constructivism) or how social reality creates people (radical constructivism, critical theory). Rather, the question is how understanding and meaning may arise in particular ways from specific kinds of dynamic constraint. (Haggis 2009, 12)

In management and organisation studies broadly, researchers have been drawing upon the analytic resources of complexity theory since the mid-1990s. One summary of this research (Tsoukas 2004) suggests that complexity has helped to transform the orientation of researchers as well as managers to notice small fluctuations or disturbances, and to appreciate how important dynamics of instability and disorder can open into changes that are generative and sustainable. Stacey's work (2005) is among many studies of organisational learning that examine what he claims to be the three key dynamics of complexity in organisations. These are the extent of information flow through the system, the connectivity among agents in the system, and diversity between agents' schemas (Stacey 2005).

Proponents of professional learning might well wonder where the individual professional has gone in these system-wide analyses. Where is professional identity and responsibility? Where is discretionary judgment? Where is the recognition of conflicting knowledge resources and regulations that professionals navigate in deciding this way or that? These issues come alive a bit more through individual case examples.

One such example worked with complexity principles of emergence and non-linear dynamics in two ways: to illuminate patterns of interdisciplinary professional practices in trying to solve a complex social problem, and to suggest educative action. The example is ISIS, a project of the Tobacco Control Research Branch in the US (Trochim et al 2006) to create a framework for public education aimed at smoking reduction. A transdisciplinary group of professionals in systems dynamics, knowledge management, tobacco control, management sciences, and health policy used complexity to frame their work around questions:

How can the flow in both directions between research and practice be optimized? How can systems ... be best characterized to be useful to the public health community? Which approaches can be used for better understanding and optimisation of networks? Through which strategies do information and knowledge become the currency for change? (Trochim et al 2006, 3)

Adopting a complexity approach, they decided to map what could be described as the sociomaterial system dynamics - not separate things like individual users, retailers and so forth, but the complex non-linear relationships affecting tobacco use, the unpredictable system-wide 
emergences, and the complicity of planning and action efforts with these emergences. The analysis then focused on the intersecting patterns of order and disorder, tracing more reductionist and more expansive patterns and thinking within the system. The project not only applied these concepts to analyze the phenomena of tobacco use, but also used complexity approaches to guide their collective learning and enquiry. Groups were gathered into concept mapping exercises, such as mapping geographies of tobacco use, mapping networks of tobacco control organisations, and even mapping their own emerging understandings about how to integrate research and practice in tobacco control. These maps were placed in interaction with one another to create systems models, which the group could adapt continually as new information emerged and as new possibilities became apparent.

In summarising the utility of complexity science for examining inter-professional practice, Thompson Klein (2004) argues that it affords a new dialogue of science and humanities, as well as new forms of knowledge and problem solving. She analyses a series of inter-professional projects in fields such as medical anthropology, the aerospace industry, and environmental research. Her analyses show that in all of these different projects, professionals need to solve problems involving a nexus of phenomena that were irreducible to one dimension. Complexity, she argues, can reveal relationships among the elements at play. The language of complexity also offers a means to break free from models of the whole derived from particular disciplinary analyses of particular parts, and enables cross-fertilisation among multiple perspectives and methods. Further, complexity concepts help to understand the various systems in play as nested. Each organises itself according to internal rules, while affecting and adapting to fluctuations interpellated through it by other systems. A key contribution to inter-professional practice and learning offered by complexity, she argues, is the interlanguage it offers among the disciplines. Emergence is this interlanguage. The focus is on not analysing independent things but tracking interrelationships among biophysical and human dimensions, policy and technology, that are integrated spatially and temporally 'at the levels of plot, household, and watershed or community’ (Thompson Klein 2004, 6).

This language of complexity appears to be particularly useful in contexts of professional education, according to various published accounts. Haggis (2008), for instance, has shown how teaching professionals complexity concepts helps them understand the simultaneities in which they must work, as well as to adopt more flexible, emergent forms of response. In social work education, Wolf-Branigin (2009) offers a case study demonstrating how complexity can support pre-service professionals to learn important capacities. These include ways to encourage connectivities among the multiple agencies and emerging social movements in particular communities, or resiliency in themselves and their clients rather than control of the solution.

In the context of collaborative professional learning, explicit teaching of complexity principles seems to afford not only insights about complex systems of practice, but also new awareness of possibilities for action. An extended example comes from education for health care professionals in interdisciplinary practice at the University of Alberta in Canada. This study showed in particular how the complexity concepts of internal diversity and nested systems were useful in developing pre-service professionals' capacity to learn collaboratively and deal with fundamental uncertainty in both their 
practice and their knowledge. Educator and researcher McMurtry $(2007,2010)$ worked in a consultative role with health care colleagues who were facilitating a mandatory course in interdisciplinary practice for undergraduate students in a range of health disciplines (nursing, occupational therapy, medicine, etc.). Important outcomes for interprofessional education of the complexity-infused curriculum included the facilitators' problematisation of the notion of consensus, which is often held to be an ideal for interdisciplinary teams. Another was participants and facilitators learning the need not to seek harmony and consensus, but to amplify the diversity of individual elements. Diversity that exists in a system, argues McMurtry, is not always recognised by participants, and complexity emphasises the importance of recognition. For interprofessional practice, this means professionals learning to make explicit the important disciplinary distinctions among their very different epistemologies, material practices and identities. To generate emergence in complexity terms, however, this explicit diversity requires sufficient 'redundancy' (overlap in purpose and knowledge among the system elements), some central purpose orienting these elements, and sufficient openness to allow the necessary trust and interaction to occur.

A further important outcome for McMurtry was the facilitators' adoption of a new pedagogical framework based on complexity's notion of nested systems to understand students, patients, system policies and politics, university interests and community resources in nested relations to one another. Thus facilitators learned to design learning activities using nested systems concepts, such as having students work through case scenarios that cut across multiple systems, to prompt student questions rather than solutions, and to foster students' (and their own) awareness of their actions' effects on different systems in which they participated, as well as their interconnectedness with these multiple systems. Nested systems also helped facilitators understand and therefore better assess the learning that emerged differently for individual students, for interdisciplinary student groups, for the entire student class, and for the larger system of the class sections and the faculty facilitators.

Taken together, McMurtry (2007) argues, these dynamics foster the trust, or more precisely the trust-within-diversity, that is critical for supporting professional knowing amidst undecidability. The most effective collaborations and the greatest emergence occurred, not through large overlaps in different professionals' knowledge, but rather when 'specialisation is allowed and encouraged, and differing professional specialisations are brought together into coherent - if not always internally homogenous - collective plans, treatments or "thoughts" through a different kind of commonality: trust' (McMurtry 2007, 91, emphasis in original).

If McMurtry focused on engaging professionals directly in complexity science principles, another approach is to use complexity principles to understand collaborative professional learning itself. One example is a study by Fazio and Gallagher (2009) of two teacher development collectives in Ontario Canada, one for secondary science teachers and one for elementary learning resource teachers, both of which the authors describe as highly functional. Fazio and Gallagher turned to complexity theory post hoc to find language and explanatory frames that could help them understand how and why significant 
professional learning outcomes had emerged from these collectives. In particular, they were trying to understand how insights emerged within the group that moved well beyond the individual expertise and experiences of the contributing members. This is the phenomenon of 'the sum exceeding its parts' that is commonly attributed to complexity adaptive systems. They found particular salience in three of Davis and Sumara's (2006) dimensions of complex systems as learning systems: (1) self-organisation (a collective of diverse elements emerging and arranging itself in unpredictable formations around a clear purpose); (2) 'bottom-up emergent' (no controlling agent or pattern, so that activities are genuinely emergent); and (3) 'ambiguously bounded' (the bounding of clear purpose unfolds within unpredictable, non-linear and often recursive developments).

One especially interesting aspect of this study is the authors' focus on the tension between the individual teachers and the collective. Teachers each practiced in diverse settings, and were conducting their own classroom inquiries through action research, integrating new curriculum materials and practices, or aligning their practices with key elements of scientific literacy. These independent inquiries involved experimenting with all sorts of complex materials and human intensities, interpreting, self-assessing, and so forth. The collective engaged in a different sort of enquiry of sharing, critiquing, and affirming, in arrangements that progressed in unanticipated ways as splinter groups formed and as topics emerged and circled back. But overall what emerged was something different again, something new in the collective as a system and the knowledge it was producing. This knowledge of course looped back into the individual inquiries, and vice versa:

the independent inquiry feeds back into collective interaction cycles, which can continue for several rounds. With each successive round, the interactions within the teacher development collective become more involved and the identities of the individual teachers become further defined.

(Fazio and Gallagher 2009, 17).

What the authors stress, finally, is that these sort of dynamics do not simply occur spontaneously. First, the teachers needed to contribute, and to recognise in themselves and others, the distinct specialist identities and expertise that each brought. This is the diversity required for emergence in complex systems. Fazio and Gallagher propose that this tension between the independent inquiries of individual teachers and the dialogue of the collective enquiry in fact helped to trigger emergence. Second, the qualities of complexity that seemed to produce the overall group effectiveness and the teacher learning needed to be promoted explicitly. In this case, a facilitator assumed this task and Fazio and Gallagher suggest this role to be key in enabling a complex system. The point is that human beings too often seek order, control, clear direction, strict boundaries and measurable outcomes. As complexity suggests with its focus on perturbation, groups of professionals may need external interruption, and may need to be pointed towards alternate, more emergent and perhaps uncomfortable approaches. 
In another study of collaborative professional learning, Zellermayer and Margolin (2005) use complexity theory to analyze the difficult processes of change experienced by supervisors (teacher educators) of elementary education student teachers. Several externally driven educational changes had unsettled the supervisors. Programmes were reorganised to adapt to declining student numbers. New requirements were mandated for student teachers as well as supervisors to conduct action research. Supervisors were expected to establish partnerships across schools. Supervisors responded differently to these changes, and there were resulting tensions within their collective. Some were curious or even excited about the new possibilities. Some felt their authority was undermined, their professional knowledge standards questioned, and their confidence shaken. Some became irritated by colleagues resistant to changing their role.

The researchers were also the facilitators who gathered volunteer supervisors to meet weekly to learn about action research. Over the course of their meetings with these supervisors, the facilitator-researchers identify what they believe to be critical events that catalysed dynamics of emergence, which eventually led to productive learning. These critical events were, primarily, moments of conflict and dissonance, featuring 'dramatic tension among the participants which provides the energy for their interaction' (Zellermayer and Margolin 2005, 1300). This reference to energy recalls Prigogine, who showed that energy is critical to shift a system to a condition far-from-equilibrium where it is capable of leaping to a new, usually unpredictable configuration. Further, however, the researchers show that in all the critical events leading towards emergence, participants became attuned to 'the periphery and to the possibility of chaos' (Zellermayer and Margolin 2005, 1300). They actually listened to dissonant views. Within the gap between, for instance, positive innovative views and negative peripheral views, the researchers argued that a learning space emerged.

The study is also useful in highlighting approaches that the facilitator-researchers believed were particularly effective in supporting professional learning in collaboration. One was identifying sources of resistance as well as collaboration. The facilitators actively catalysed confrontations that they believed could spark learning and group development through dissonance. They hasten to note that the group dialogue needs to explicitly support those taking risks and those suffering anxiety, while actively encouraging these expressions of difference. Further, they suggest providing opportunities for participants to 'zoom in' on their emotions and to 'zoom out on their learning', to see it in a wider theoretical context (Zellermayer and Margolin 2005, 1304). Finally they remind readers that individual participants don't all learn simply by being part of a collective undergoing emergence.

\section{Discussion: Contributions and Limitations of Complexity Science}

Taken together, these examples of complexity science employed in analyses of collaborative professional practice and learning have emphasised the utility of four concepts in particular: emergence, diversity, self-organisation and nested systems. Emergence through non-linear, decentralised interaction was treated as a central concept, employed in various ways. For Trochim et al. (2006) and the inter-professional group 
charged with finding ways to influence smoking cessation, emergence provides a way to truly see. Its tools helped them to see the continual unpredictable changes in the patterns of all the elements contributing to the problem, as well as the continual interactions among them - social norms, spatial arrangements, consumer attitudes, industry marketing, economic and policy factors. Emergence also offered these researchers approaches to 'mapping' that are dynamic rather than static. These maps could capture nuanced interconnected shifting patterns, including the shifts caused through the researchers' own co-implications in these patterns. For Thompson-Klein, emergence provides an inter-language that helps diverse professionals working collaboratively to break out of their own analytic, specialist models and track inter-relationships among phenomena. In the collaborative learning of teacher supervisors, Zellermeyer and Margolin (2005) actively sought to induce emergence, which they believe is the condition of possibility for productive learning. Key to this condition, they argue, is perturbation. This occurs particularly through dissonance that arises naturally among the group but that is deliberately held open and mediated by facilitators.

A second recurring principle of complexity in these studies is the emphasis on internal diversity. The dissonance so critical in the collaborative professional learning observed by Fazio and Gallagher (2009) depended on diversity within the group. But diversity isn't always explicitly recognised by people in a group, or it may be overlooked in the natural human press to seek consensus. Or, professionals may simply not be accustomed or inclined to engage the difficult diversity of different knowledge claims among an interprofessional group. The facilitators worked to draw attention to people's different experiences and epistemic framings, and their ways of expressing these. At the same time, they encouraged sufficient interaction among these different orientations to enable new ideas to emerge. McMurtry (2007) also found that professionals learning to collaborate inter-professionally do better when they actively recognise their respective diversity in values and languages, rather than seeking to immediately find commonality. Not just recognising, but learning to be explicit about one's own expertise, and explicitly engaging others' diverse expertise, were critical processes for enabling emergence. Thus, returning to this central complexity dynamic of emergence, the registering and mediation of internal diversity enables not only an expansion of knowing, but also the emergence of new (inter-professional) practices, and objects of practice.

The notions of self-organisation and nested systems also appeared to be particularly useful for the researchers in these studies. Both Wolf-Branigin (2009) in social work education and McMurtry (2010) in health care education, for instance, showed that one of the more successful outcomes of inter-professional education arose through explicit teaching of how nested systems work in health care practice. Students learned complexity language to trace the nestings of different systems of knowledge, professional communities, stakeholders, families, public and private organisations. Trochim et al.'s (2006) example of inter-professional work to address public smoking also showed how understanding the contributing dynamics as nested systems helped to delineate the lines of emergence - how these systems together were creating and amplifying particular patterns mobilising tobacco consumption. Furthermore, in all of these cases, a focus was on encouraging professionals themselves to become attuned to their own co-implication 
in the nested systems in which they practiced. These complexity concepts, suggest these authors, invite professionals to become more finely attuned to the effects of their own actions, to recognise the system of particular professional values, rationalities and regulation within which their actions arise and circulate, and to appreciate the nested interactions of these with other systems comprising their worlds of practice. Complexity therefore becomes a sensibility, a way for professionals to understand themselves as part of an emerging system, nested within myriad systems. In particular, as Davis and Sumara (2006) claim, complexity can claim to focus people with more acuity on the everyday mundane perturbations of their worlds of practice, appreciating what emerges and how, attuning to surprise within these webs of relations, and developing more mindful ways of participating.

However, the question remains of how power flows within a system to enact particular entities, positions and rewards. Power may appear to flow through the system according to ways people take up positions and understand others' positions in relation to themselves. The positions are in constant flux for they change each time someone turns to a new activity or subject. The consequent directions of power and changing locations influence different individuals' ability to participate meaningfully in the systems. Individuals potentially become vulnerable to a few who manipulate the system's activities to sustain their own power, ensuring that their experiences become the most valued knowledge in the collective. Phelan (2004), a curriculum theorist, raises important concerns about applying complexity too quickly to questions of learning.

It is the paradoxes of complexity science that entice and trouble me at the same time. Consider the notion of internal diversity as the source of a system's intelligence. The system, however, tends towards coherence. How is that coherence arrived at? Are some of those diverse ideas eliminated, contained or resolved? ... Why might particular forms of learning unfold? How do the "emerging" ideas serve the interests of some and not others? (Phelan 2004,14)

Particularly in considering professional practice and learning, as Evetts (2009) argues, problematic changes are being influenced by governmentalities associated with new public managerialism: output controls, standardised performance measures, discourses of enterprise and a general shift to 'organisational professionalism'. New regulatory regimes are reconstituting professional practice and knowledge. Such political dynamics appear to be invisible to the constructs of complexity theory. This is evident in the example from Zellermayer and Margolin (2005). Overall this study focused on ways to hold open the tensions in a system, in order to enable the perturbations and interactions that encourage new relationships and knowledge to emerge. However, the study also begs larger questions of power and politics. Controlling regimes for professionals such as these teacher educators are political systems competing with the educators' systems of dialogue and learning.

Complexity purports to trace the ongoing matter-ing dynamics of the world that both reveal and create 'what matters'. But 'what matters' is invariably linked with critical dynamics of power relations, on which complexity may be ultimately silent. This silence may sidestep key questions needed about inter-professional practice. What forms of 
professional knowledge and activity are granted the greatest visibility and influence over the movements and directions of the system? Whose interests are most advantaged or disadvantaged by the patterns that emerge? What subjectivities and rationalities are assembled or constrained by regulatory technologies at work? And for those animated by more activist concerns, how can better conditions for professionals and the people they serve - more generative, open, fair and life-sustaining - be induced in a complex system, or at least be available as possibilities?

One response to the charge that complexity does not speak to concerns of politics, equity or justice is simply that it never intended to.

$[\mathrm{C}]$ omplexity theory, while acknowledging that selfish intention can give rise to horrible wrongs, is more prone to regard the injustices of the world as inevitable consequences of complex dynamics. Unequal distributions of wealth and power, argue complexivists, are not only inevitabilities; these are phenomena that are given to self-amplification ... The rich will get richer, the advantaged will gain more advantage - not because of intention, but because of the laws of nonlinear dynamics.

(Davis and Sumara 2008, 169-70)

Further, within the existing literature examining professional practice with complexity theory, there seems to be little attention paid to pernicious phenomena and organisations that grow and adapt quickly to wreak destruction, from epidemiological systems such as HIV-aids to extreme right-wing political groups. Benign assumptions sometimes underpin analyses, as though complex systems generate novel patterns and meanings in an inherently balanced and productive way. Much more could be said about the potentially harmful effects where problematic elements in a system are amplified, where system feedback becomes looped to create uncontrollable growth or obsession, or simply where system emergence produces undesirable effects in practices, knowledge, objects or subjectivities.

\section{Reconsidering Complexity to Analyze Professional Learning: Questions and Directions for Future Research}

Given these problems, can complexity theory truly be useful in analysing professional learning? What contributions can it make, particularly to the topics of focus in this discussion on professionals learning in and for collaborative practice? Two points are argued here in response to this question. The first is that complexity theory in studies of professional practice and education such as those outlined above has already demonstrated important insights for collaborative professional learning. The second is that complexity analyses can do much more to exploit the explanatory power of complexity concepts, by returning to rich dynamics of emergence in a sociomaterialist analysis, and by avoiding metaphorical uses of complexity. Used rigorously rather than romantically, complexity concepts may be useful not only in analysing political dynamics of collaborative professional practice, but also in opening new questions and approaches for future research in professional learning. 
To the first point, the foregoing discussion of existing studies suggests that principles of complexity seem to be undertaking two main kinds of work in the project of understanding and promoting professional learning and practice in collaboration. The first could be described as articulating the changing complexities of professional practice and knowing. Using complexity concepts of emergence, diversity, self-organisation and nested systems, researchers have shown how the dynamic multiplicities of practice resist universalist procedures and standards. In the complex adaptive systems comprising professional practice, the non-linear dynamics at play mean that a series of choices is available at each moment, to each and every interacting element of the system, human and nonhuman (Prigogine 1997). Not only are choices being made by these entities in ways that are not accessible to human consciousness, but also the forces affecting these choices are often not visible, or even present, in the system at any given moment. Once a choice is made, it is irreversible - because that choice immediately spawns a new set of choice-making activities among entities affected by that choice. Novel patterns are continually emerging in surprising ways that often refute expectations of causality.

The result is an undecidability for practice, for knowledge, and for education (Osberg, Biesta and Cilliers 2008). The problem for professionals is the more common expectation that they should solve problems, using 'evidence' obtained from past practice and distant contexts. Such evidence-based knowledge is not about adapting with emerging complexity, but about prediction and control. Complexity diverts emphasis away from representations of knowledge, away from 'solutions' and 'evidence-based practice', to accepting the radical contingency of practice itself. Within this contingency that complexity shows to be the condition of all living systems, educational analysts using complexity have highlighted the continuous possibilities - the logic of renewal in Osberg's terms (2008) - in everyday practice.

Therefore the second contribution of complexity might be described as providing educational support for professional knowing and responsibility within this undecidability of professional practice. As evidenced by studies here, complexity principles have been used to understand and support the difficulty of professionals' learning in collaboration. Like most professional practice this demands action within essentially undecidable circumstances. Complexity principles also have been taught to professionals to help them negotiate this continual surprise and ambiguity. They learn to attune to emergences and perturbations, to appreciate the uncertain and sometimes uncomfortable dynamics in which they participate, and to engage new possibilities rather than control them. Professional education and learning has been informed by complexity to counter linear frameworks, to invite experimentation, to amplify emerging patterns, and to focus more on knowing-in-practice rather than knowledge acquired through predetermined models.

Turning to the problem of complexity's apparent silence on questions of power relations in professional knowledge and practice, some have argued this to be a consequence of applying a metaphor of complexity to social science (Byrne 2005; Osberg and Biesta 2007). That is, in the hands of some researchers, complexity concepts such as emergence, self-organisation, connectivity and so forth have been abstracted from material processes and turned into 
representations considered desirable. These representations have then been projected interpretively onto dynamic social systems to produce notions like positive human interconnections and continuous creativity. Such metaphors conserve the very anthropocentric ontology that sociomaterial approaches seek to disrupt, and maintain a divide between social and material/natural reality. They also leave the tools of social science investigation relatively unchanged.

In fact even in the study examples selected here, the emphasis appears often to focus on socio-personal rather than sociomaterial processes of learning. Although complexity's terms and approaches are fundamentally rooted in the biological, this materiality is noticeably absent in some complexity studies of professional practice, which tend to remain a little too much at the level of metaphor in their applications of complexity. Complexity analysis may be strengthened by returning to empirical tracings of the sociomaterial assemblages through which force is exercised. Non-human materiality, inter-penetrated by human activity, constitutes professionals' worlds at every level. Nuanced analyses could trace concretely how human and nonhuman things - texts, intentions, instruments, technologies, languages, schedules, buildings - together create, stabilise, disrupt and transform particular professional practices.

Such complexity analyses can reveal dynamics that are at play but often overlooked in collaborative professional learning processes, such as oppression, exclusion and agonism. Walby (2005), for example, uses the concept of nested systems to analyse how social inequalities (e.g. gender, class, ethnicity) emerge through social and material relations in non-linear self-organising dynamics. Then she shows how these systems intersect with institutionalised structures (economy, polity, violence etc) to produce particular actions. This kind of sociomaterial analyses of nested systems might be useful in tracing how political dynamics are affecting professionals such as the teacher supervisors described by Zellermayer and Margolin (2005).

Complexity approaches also, argues political ecologist Bennett (2010), can illuminate openings for change, opportunities for interruption, and strategies for productive coalitions. Bennett $(2010,107)$ shows that a materialist theory of democracy is enabled when we appreciate the world 'as a swarm of vibrant materials entering and leaving agentic assemblages'. The power to disrupt and change the 'sensible' taken-for-granted which so often preserves inequities in voice, resource distribution and knowledge recognition - is not limited to human speakers. Disruption involves assemblages of nonhuman forces, from technologies, texts and instruments to disease and natural disasters, as well as human values, dialogue, and choice. When regimes are disrupted, new tactics emerge for enhancing, or weakening, particular arrangements (Bennett 2009).

In much professional work, it's clear that regulatory agencies, audit regimes, increased public expectations, and depleted resources are constricting professionals' spaces for care and creativity. But the dynamics of emergence require continuous improvisation, choice and interconnectivity among all elements, social and natural, of a system. Complexity researchers might concentrate on tracing precisely how openings become available for professionals' creative choices within the very sociomaterial dynamics - and reductions - 
of the complex systems in which they are embedded. As Barad $(2003,827)$ writes, '[p]articular possibilities for acting exist at every moment, and these changing possibilities entail a responsibility to intervene in the world's becoming, to contest and rework what matters and what is excluded from mattering.'

For professional learning and practice, a rigorous engagement with complexity's emergentist ontology radically calls into question the material separation of humans, objects and their relations, including the separation of entities and representations. It also insists that the future is radically open, for at every local performance of intra-action, there is space for material-discursive agency. This deeper complexity analysis, eschewing metaphors and recovering the intricate sociomaterial dynamics of emergence, could contribute far more richly to the dual project evident in existing studies: articulating complexities of collaborative professional practice, and providing educational support for professional knowing-in-undecidability. Further, as argued here, complexity research that is grounded more carefully in the actual dynamics of radical contingency, irreversibility, nested systems and strong emergence could offer important insights about the circulations of power and the intersections of conflicting system interests. Such complexity analysis may point to new possibilities for professional action, new forms of knowing, and even new questions of responsibility within what are increasingly acknowledged to be repressive conditions for professional practice. Finally, a more rigorous, more sociomaterial complexity analysis may help move forward the useful work already undertaken in some studies mentioned here (McMurtry 2007, WolfBranigin 2009) in addressing professional education for collaborative practice.

To rephrase questions asked by Osberg and Biesta (2007), What would professional development look like if knowledge were truly appreciated as unfolding in processes of action that brings forth new worlds? What could occur if professional education were less concerned with what and how content should be presented, and focused on being a tool itself for emergence? What if education compelled professionals as well as researchers 'to consider how we are implicated in the phenomena that we encounter-and, more broadly, to acknowledge that our descriptions of the world exist in complex (i.e., nested, co-implicated, ambiguously bounded, dynamic, etc.) relationship with the world' (Davis and Sumara 2008, 183). This sort of complexity approach moves well beyond metaphorical notions of flow and interconnectedness to suggest professional collaboration as spaces of intra-activity and disruption, where knowledge is brought forth with the appearance of distinctions among phenomena and identities. Professional learning in and for collaboration might then be understood, through a rich complexity approach, as sites of sociomaterial struggle, realising different agential possibilities in 'the ongoing open process of mattering' (Barad 2003, 817) that gives form and meaning to professional practice.

\section{References}

Alhadeff-Jones, M. 2008. Three generations of complexity theories: nuances and ambiguities. 
Educational Philosophy and Theory 40, no.1: 66-82.

Bai, H. 2001. Beyond the educated mind: Towards a pedagogy of mindfulness, body and mind. In Body and mind: Exploring possibility through education, ed. B. Hocking, A. Haskell and W. Linds, 86-99.Vermont, NH: Foundation for Educational Renewal.

Barad, K. 2003. Posthumanist performativity: toward an understanding of how matter comes to matter. Signs: Journal of Women in Culture and Society, 28, no. 3: 801-831

Barton, D. and Hamilton, M. 2005. Literacy, reification and the dynamics of social interaction. In Beyond Communities of Practice: Language, power and social context, ed. D. Barton and K. Trusting, 14-36. Cambridge: Cambridge University Press.

Bennett, J. 2010. Vibrant matter: a political ecology of things. Durham NC: Duke University Press.

Bolam, R., McMahan, A., Stoll, L., Thomas, S., and Wallace, M. 2005. Creating and sustaining professional learning communities. General Teaching Council of England/Department for Education and Skills/ University of Bristol

Byrne, D. 2005. Complexity, configurations and cases. Theory Culture Society 22, no. 5: 95-111.

Davis, Brent. 2004. Inventions of teaching: A genealogy. Mahwah, NJ, Erlbaum.

Davis, B. and Sumara, D.J. 2000. Curriculum forms: On the assumed shapes of knowing and knowledge. Journal of Curriculum Studies 32, no. 6: 821-45.

Davis, Brent and Dennis J. Sumara. 2006. Complexity and education: Inquiries into learning, teaching and research. Mahwah, NJ: Erlbaum

Davis, B. and Sumara, D. 2008. The death and life of great educational ideas: Why we might want to avoid a critical complexity theory. Journal of the Canadian Association for Curriculum Studies 6, no. 1:

Dufour, Richard and Robert Eaker. 1998. Professional learning communities at work: best practices for enhancing student achievement. Bloomington: National Education Service.

Edwards, A., Daniels, H., Gallagher, T., Leadbetter, J., and Warmington, P. 2009. Improving inter-professional collaborations: Multi-agency working for children's wellbeing. London: Routledge.

Engeström, Y. 2007. From communities of practice to mycorrhizae. In Communities of practice: Critical perspectives, ed. J. Hughes, N. Jewson and L. Unwin. London: Routledge. 
Evetts, J. 2009. New professionalism and new public management: Changes, continuities and consequences. Comparative Sociology 8: 247-266.

Fazio, X. and Gallagher, T.L. 2009. Supporting learning: An examination of two teacher development collectives. Complicity: An International Journal of Complexity and Education 6, no. 1: 1-19.

Fenwick, T. 2001. Questioning the concept of the learning organization. In Knowledge, power and learning, ed. C. Paechter, M. Preedy, D. Scott and J. Soler, 74-88. London: SAGE.

Fenwick, T. 2009. Responsibility, complexity science and education: Dilemmas and uncertain responses. Studies in Philosophy and Education, 28, no. 2: 101-118.

Frankham, J. 2006. Network utopias and alternative entanglements for educational research and practice. Journal of Education Policy 21, no. 6: 661 - 677.

Haggis, T. 2008. Knowledge must be contextual: Exploring some possible implications of complexity and dynamic systems theories for educational research. Educational Philosophy and Theory, 40, no. 1: 159-176

Haggis, T. 2009. Beyond mutual constitution: looking at learning and context from the perspective of complexity theory. In Rethinking contexts for learning and teaching: Communities, activities and networks, ed. R. Edwards, G.J.J. Biesta, and M. Thorpe. London: Routledge

Karpiak, I. 2000. Evolutionary theory and the new sciences. Studies in Continuing Education, 22, no. 1: 29-44.

Mason, Mark. 2008a. (ed) Complexity theory and the philosophy of education. Bognor Regis, UK: Wiley-Blackwell.

Mason, M. 2008b. Complexity theory and the philosophy of education. Educational Philosophy and Theory, 40, 1: 4-18.

McMurtry, A. 2007. Complexity science and the education of interdisciplinary health teams, unpublished doctoral thesis. Edmonton, Alberta: University of Alberta.

McMurtry, A. 2010. Complexity, collective learning and the education of interdisciplinary health teams: Insights from a university-level course. Journal of Interprofessional Care 24, no. 3: 220-229

Osberg D. 2008. The logic of emergence: An alternative conceptual space for theorizing critical education. Journal of the Canadian Association for Curriculum Studies 6, no.1: 133-161

Osberg D.C and Biesta, G.J.J. 2007. Beyond presence: Epistemological and pedagogical implications of strong emergence. Interchange 38, no.1: 31-51 
Osberg, D.C. and Biesta, G.J.J. 2008. The emergent curriculum: Navigating a complex course between unguided learning and planned enculturation. Journal of Curriculum Studies 40, 3: 313-328.

Osberg, D.C., Biesta, G.J.J., and Cilliers, P. 2008. From representation to emergence: Complexity's challenge to the epistemology of schooling. Educational Philosophy and Theory 40, no.1: 213-227

Paley, J. 2007. Complex adaptive systems and nursing. Nursing Inquiry 14, no. 3: 233 242

Phelan A.M. 2004. Rationalism, complexity science and curriculum: A cautionary tale. Complicity: an International Journal of Complexity and Education 1, no. 1: 9-17

Prigogine, Ilya. 1997. The end of certainty: Time, chaos, and the new laws of nature. New York: The Free Press.

Smith, J. and Jenks, C. 2005. Complexity, ecology and the materiality of information. Theory Culture and Society 22, no. 5: 141-163.

Stacey, Ralph.D. 2005. Experiencing emergence in organizations: Local interaction and the emergence of global patterns. London: Routledge.

Thompson Klein, J. 2004. Prospects of transdisciplinarity. Futures 36: 515-526.

Trochim, W.M., Cabrera, D.A., Milstein, B., Gallagher, R.S., and Leischow S.J. 2006. Practical challenges of systems thinking and modeling in public health. American Journal of Public Health 96, no. 3: 538-546.

Tsoukas, Hari. 2004. Complex knowledge studies in organizational epistemology. Oxford: Oxford University Press.

Walby, Sylvia. 2009. Globalization and inequalities: Complexity and contested modernities. London: Sage.

Wolf-Branigin, M. 2009. Applying complexity and emergence in social work education. Social Work Education 282: 115-127.

Zellermayer, M., and Margolin, I. 2005. Teacher educators' professional learning described through the lens of complexity theory. Teachers College Record 107, no. 6: 1275-1304. 